\title{
EDITH MANNING SHIMKIN, 1912-1984
}

Born in New Orleans, the daughter of an officer in the U.S. Public Health Service, Edith Manning grew up in an atmosphere of concern for human welfare. Her family traveled widely and held an international outlook. She attended the College of William and Mary but graduated from George Washington University in 1934, after finances had forced a transfer. Her first employment, the beginning of lifelong work as an editor, analyst, and translator, was with the National Geographic Society. She helped John Oliver La Gorce edit the famous Book of Fishes (1939).

Between 1941 and 1943 she was employed as an analyst in the Military Intelligence Division of the War Department General Staff. Her most important contribution was a detailed and accurate assessment of the Soviet petroleum situation for Determination of Fighting Strength of the USSR, a basic document prepared for, and used in planning by, the Combined Chiefs of Staff in the spring of 1942.

After a period devoted to family responsibilities, Edith Shimkin undertook graduate study in law, Russian history, and Russian language and literature at George Washington University and the University of Illinois. Her intellectual interest in the Soviet field focused on archeology. Between 1968 and 1980 she undertook a series of technical studies on radiocarbon measurements in the USSR. In 1972 and in 1975, jointly with Demitri Shimkin, she published major review articles on Soviet Central Asia and on northeastern Siberia. Most important, and well acknowledged by Soviet archeologists, was her interpretative monograph "The Upper Paleolithic in North Central Eurasia: Evidence and Problems," pp. 193-315 of Leslie Freeman, ed., Views of the Past (The Hague: Mouton, 1978). She edited and translated a special issue of the Journal of the Steward Anthropological Society, "Contributions to Inner Asian Anthropology," in 1981. This publication brought to scholarly attention in the West hitherto inaccessible data from both prerevolutionary and Soviet field investigations. At the time of her death from cancer, Edith Shimkin was preparing to translate and edit a comprehensive study of The Ancient Art of Northern Asia by Anatolii I. Martynov of Kemerovo State University in the USSR. This study, accepted for publication by the University of Illinois Press, will be brought to completion posthumously.

Despite increasing illness from rheumatoid arthritis and the pain caused by the loss of a son who, as a correspondent in Vietnam, was reported missing in action in 1972, Edith Shimkin remained professionally active to the end. From 1970 on she was an associate of the Russian and East European Center of the University of Illinois, directing the Research Colloquium and helping many graduate students. She was a member of the National Slavic Honor Society, American Oriental Society, American Anthropological Association, and the American Association for the Advancement of Slavic Studies.

Demitri B. ShIMKIN

University of Illinois at Urbana-Champaign 